\title{
SYNTHESIS OF BARIUM TITANATE PIEZOELECTRIC CERAMICS FOR MULTILAYER ACTUATORS (MLAs)
}

\author{
Mojtaba BIGLAR*, Magdalena GROMADA**, Feliks STACHOWICZ*, Tomasz TRZEPIECIŃSKI* \\ *Faculty of Mechanical Engineering and Aeronautics, Department of Materials Forming, Rzeszow University of Technology, \\ Powst. Warszawy 12, 35-959 Rzeszów, Poland \\ ${ }^{*}$ Institute of Power Engineering, Ceramic Department CEREL, Research Institute, ul. Techniczna 1, 36-040 Boguchwała, Poland \\ $\underline{\text { m biglar@prz.edu.pl, gromada@cerel.pl, stafel@prz.edu.pl, tomtrz@prz.edu.pl }}$
}

received 4 May 2015, revised 21 November 2017, accepted 24 November 2017

\begin{abstract}
In this paper the characteristics of $\mathrm{BaTiO}_{3}$ ceramics synthesized by solid state method is presented. In order to receive the monophase ceramics the double activation and calcination were applied. A spray drier was used to granulate the powder of $\mathrm{BaTiO}_{3}$. Isostatic and uniaxial pressing were applied to manufacture the barium titanate pellets. The properties of fabricated $\mathrm{BaTiO}_{3}$ ceramics were determined at different stages of production. After the sintering phase, the hardness, the bending strength, the fracture toughness, and the coefficient of thermal expansion of barium titanate sinter were estimated. The $\mathrm{BaTiO}_{3}$ powder is characterized by spherical grains and the average size of $0.5 \mu \mathrm{m}$. The small value of the specific surface area of granulate ensured good properties of material mouldability and finally allowed to receive sinters of high density.
\end{abstract}

Key words: Barium Titanate, MLAs, Multilayer Actuators, Solid State, Piezoelectric Ceramics

\section{INTRODUCTION}

Barium titanate, revealing both ferroelectric and piezoelectric properties, is a very desirable perovskite-type ceramic material in the field of electroceramics and microelectronics (Biglar et al., 2015; Vijatović et al., 2008). BaTiO3 is destined for many applications in different industries, such as energy storage devices and multilayer actuators (MLAs) (Miot et al., 1995; Kao and Yang, 1999). These applications require materials with a good density, a high dielectric constant and a low loss factor. $\mathrm{BaTiO} 3$ has become one of the most important ferroelectric material. At Curie temperature the barium titanate transforms from paraelectric to ferroelectric phase (Ertuğ, 2013). Synthesis of materials with these properties needs highly pure, fine grained ceramics, which may be obtained from homogeneous reproducible powders of spherical particles (Miot et al., 1995; Kholodkova et al., 2012).

Choi et al. (2008) underline that MLCs have been investigated because their advantages are high precision, little noise and low power consumption, compared with conventional multilayer actuators (MLAs). Two types of multilayer actuators are considered, namely, stacked-disk and co-fired (Yoshikawa and Shrout, 1993). Fine grain powders used for fabrication piezoelectric materials has an effect on lower driving voltages and higher driving fields (Hackenberger et al., 1998; Luo et al., 2011).

The properties of barium titanate have been the subject of study of many authors (i.e., Cai et al., 2011; Prado et al., 2016; Zheng et al., 2012). The powder fabrication method and the synthesis procedure strongly influence the features of barium titanate (Moura et al., 2009; Stojanovic et al., 1999; Vijatović et al., 2008).

A lot of synthesis methods have been developed for the preparation of barium titanate powders. Both the conventional solid state reaction methods, chemical methods and mechanochemical used to prepare barium titanate have been described in the literature. Large scale production is based on solid state reactions of mixed powders $\mathrm{BaCO} 3$ and $\mathrm{TiO} 2$ at high temperatures. However, this procedure results in agglomeration, poor chemical homogeneity and formation of secondary phases which harm the electrical properties of $\mathrm{BaTiO3}$ (Kim et al., 2009, Othman et al., 2014). However, the solid state method has the advantages of low production cost, precise stoichiometry control, operating simplicity and possibility of its application on mass production (Kao and Yang, 1999; Kholodkova et al., 2012).

Considering the disadvantages of solid state method, searching for development of barium titanate synthesis techniques was widely described by other authors. Wet-chemical methods at the temperature less than $100^{\circ} \mathrm{C}$ were applied for obtaining of 50-60 $\mathrm{nm}$ particles (Kholodkova et al., 2012). Nguyen et al. (2007) have developed the hydrothermal synthesis. This technique is used for producing oxide layers on ceramic surfaces. The main advantages of hydrothermal method is a simple procedure and low temperature treatment.

In this paper, the fabrication method and properties of barium titanate ceramics are described. The powder of $\mathrm{BaTiO} 3$ is synthetized by solid state method. The goal of the investigation is to prepare suitable material for MLAs. At the end of the paper, all properties influencing the application of obtained material for the multilayer actuator were discussed.

\section{EXPERIMENTS}

The powder of barium titanate was fabricated from the $\mathrm{TiO}_{2}$ ( $99 \%$ of purity, Kronos, USA) and $\mathrm{BaCO}_{3}(99.5 \%$ of purity, Chempur, Poland). The raw materials were mixed with isopropyl alcohol 
and milled in the mixer mill for two hours. The obtained powder was calcined in the electrical furnace for 8 hours at $1100^{\circ} \mathrm{C}$. The double milling and calcination were necessary to obtain monophase material. The diffraction patterns were recorded by $X$-ray X'PertPROX diffractometer equipped with a detector of $\mathrm{Cu} \mathrm{Ka}$ radiation. The particle size distribution of powder was determined using Mastersize 2000 (Melvern, United Kingdom). The specific surface area of powders was determined by using Autosorb-1 analyzer (Quantachrome, USA).

The morphology of powder was evaluated based on the SEM micrographs made by using HITACHI S-3400N/2007 microscopy. To ensure good mouldability the $\mathrm{BaTiO}_{3}$ powder was granulated with the use of Niro spray drier (GEA, Germany). The spray pressure was equal to the equivalent of $40 \mathrm{~mm}$ water column. The values of inlet and outlet temperatures were equal to $220^{\circ} \mathrm{C}$ and $80^{\circ} \mathrm{C}$, respectively. The properties of received granulate i.e., the specific surface area and the phase composition were also determined. The isostatic and uniaxial pressing is used to manufacture the $\mathrm{BaTiO}_{3}$ pellets.

The green pellets were sintered in the electrical furnace. The dilatometric curves were used to ensure the suitable sintering conditions. The maximal sintering temperatures were 1250, 1300, 1350,1400 and $1450^{\circ} \mathrm{C}$. The both cooling and heating rates were set to $100^{\circ} \mathrm{C} / \mathrm{h}$. Sintered pellets were denoted, respectively: Ba$\mathrm{TiO}_{3}(0), \mathrm{BaTiO}_{3}(1), \mathrm{BaTiO}_{3}(2), \mathrm{BaTiO}_{3}(3)$ and $\mathrm{BaTiO}_{3}(4)$.

The parameters characterizing the extent of material sintering: the apparent density, the apparent porosity, the water absorbability were estimated for sintered pellets by method taking advantages of Archimedes law. In the next stage, the pellet of the average density, sintered at $1300^{\circ} \mathrm{C}\left(\mathrm{BaTiO}_{3}(1)\right)$ was considered and characterised in the direction of XRD and SEM.

The mechanical properties such as the hardness, the bending strength and the fracture toughness, and the coefficient of thermal expansion were determined based on the fabricated beams. These beams were manufactured according to the procedure used to fabricate $\mathrm{BaTiO}_{3}(1)$ pellets. The linear expansion coefficient was determined using a dilatometer (BÄHR-Gerätebau, Germany). The fracture toughness and Vickers hardness of Ba$\mathrm{TiO}_{3}(1)$ were performed on 430/450SVD testing machine (Melit, Switzerland). The flexural strength of $\mathrm{BaTiO}_{3}(1)$ specimen was determined on a standard universal testing machine Z030 (Zwick/Roell, Germany) equipped with a 3-point bending device.

\section{RESULTS AND DISCUSSION}

The XRD pattern of powder of $\mathrm{BaTiO}_{3}$ is shown in Fig. 1. The peaks of synthesized powder very well overlap with the standard ones. So, it was found that to obtain monophase powder the two mechanical activation and calcination processes are necessary.

An analysis of the morphology of barium titanate presented in Fig. 2a led to conclude that powder was characterized by uniform structure. The dimensions of the individual grains are very similar and equal to $0.5 \mu \mathrm{m}$ (Fig. 2b). The small number of grains have an average diameter of about $1 \mu \mathrm{m}$.

In the Fig. 3 the distribution of particle size of $\mathrm{BaTiO}_{3}$ powder is presented. The particle size distribution ranged between $0.3 \mu \mathrm{m}$ and $80 \mu \mathrm{m}$.

However, the average particle size was equal to $1.59 \mu \mathrm{m}$. The grains of $\mathrm{BaTiO}_{3}$ powder had a tendency to create agglomerates. The average size of the separate grain is almost three times smaller than the size of particles of agglomerates. The similar conclusion was found by Yoon and Lee (2004) who analysed the mean particle size and specific surface area of barium titanate fabricated also by solid state technique. In our investigations the specific surface area of powder particles was equal to approximately $1.9 \mathrm{~m}^{2} / \mathrm{g}$. Presented in Fig. 4 the XRD pattern of granulate, reveals also very well convergence to the standard pattern.

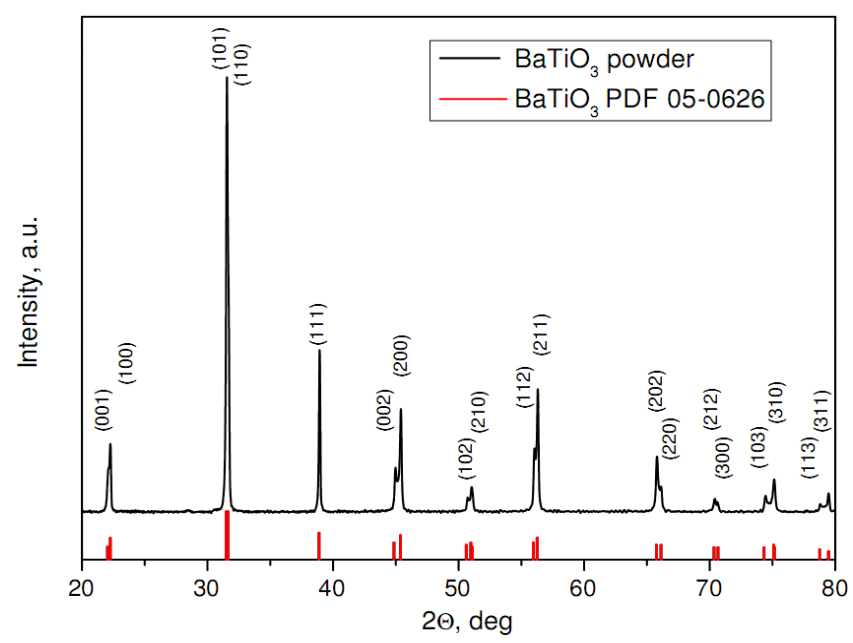

Fig. 1. XRD pattern of $\mathrm{BaTiO}_{3}$ powder

a)

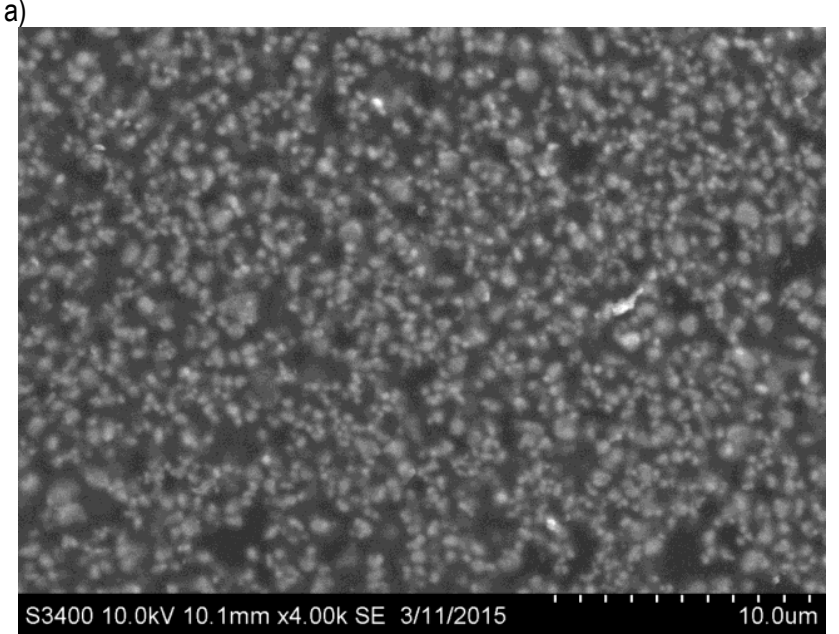

b)

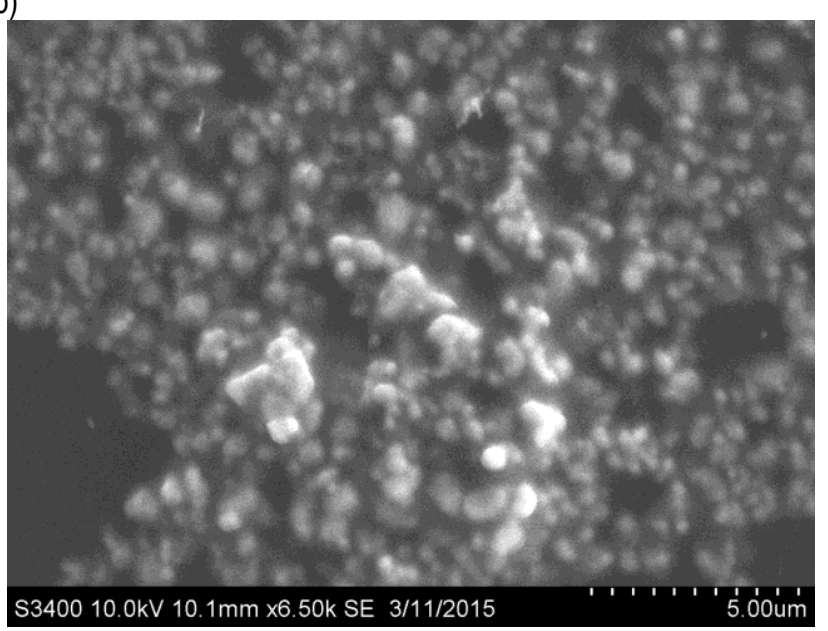

Fig. 2. SEM morphology of $\mathrm{BaTiO}_{3}$ powder in two different magnifications: $x 4.00 \mathrm{k}(\mathrm{a})$ and $\times 6.50 \mathrm{k}(\mathrm{b})$ 


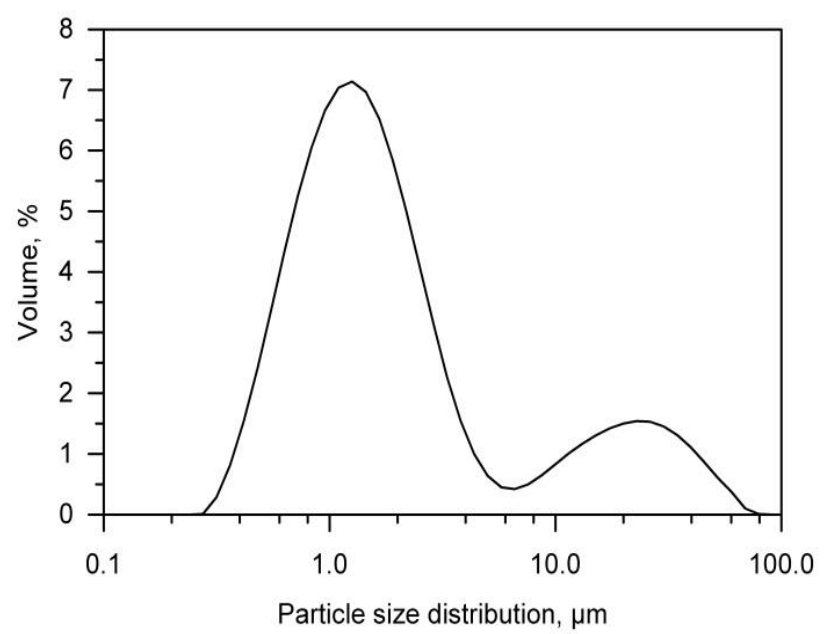

Fig. 3. The particle size distribution of $\mathrm{BaTiO}_{3}$ powder

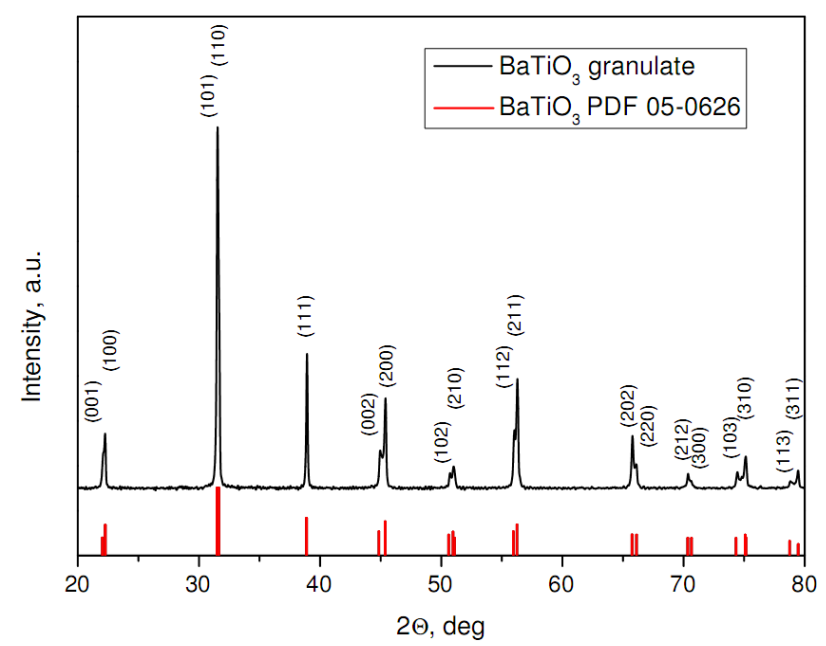

Fig. 4. XRD pattern of $\mathrm{BaTiO}_{3}$ granulate

From data shown in Tab. 1 and Fig. 5 follows that the values of water absorbability and the apparent porosity of sintered pellets increase together with the maximal sintering temperature. The value of water absorbability increases with the sintering temperature (Tab. 1). Furthermore, the increasing in sintering temperature led to an increase of the apparent porosity (Fig. 5). In the range of apparent density between 5.80 and $5.87 \mathrm{~g} / \mathrm{cm}^{3}$ the values of apparent porosity are very similar. The values of relative density evaluated as the ratio of apparent density to the theoretical density are very similar (Table 1). Duran et al. (2002) and Miot et al. (1995) found that density of $\mathrm{BaTiO}_{3}$ sintered pellets based on the value of lattice constant is equal to $6.02 \mathrm{~g} / \mathrm{cm}^{3}$. So, the obtained relative density is in agreement with the results of other authors.

Tab. 1. The physical properties of sintered pellets

\begin{tabular}{|c|c|c|}
\hline Material type & Relative density, $\%$ & Water absorbability, $\%$ \\
\hline $\mathrm{BaTiO}_{3}(0)$ & 97.01 & 0.03 \\
\hline $\mathrm{BaTiO}_{3}(1)$ & 96.68 & 0.05 \\
\hline $\mathrm{BaTiO}_{3}(2)$ & 96.84 & 0.06 \\
\hline $\mathrm{BaTiO}_{3}(3)$ & 96.35 & 0.07 \\
\hline $\mathrm{BaTiO}_{3}(4)$ & 97.51 & 0.09 \\
\hline
\end{tabular}

As we can see from the Fig. 6 the grains of barium titanate granulates exhibit a spherical shape that the dimensions varied between $25 \mu \mathrm{m}$ and $35 \mu \mathrm{m}$. The spherical shape of granules is a result of granulation process. Before this process the $\mathrm{BaTiO}_{3}$ powder was mixed with additives. So, the dimensions of powder granules did not change. During the granulation process the water slurry was sprayed. The specific surface area of $\mathrm{BaTiO}_{3}$ granulate $\left(1.18 \mathrm{~m}^{2} / \mathrm{g}\right)$ is smaller than in the case of powder.

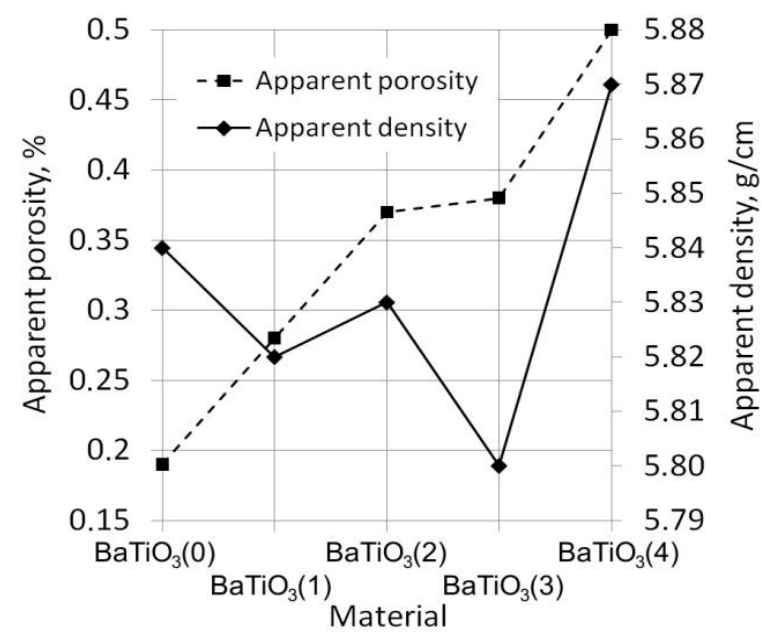

Fig. 5. Effect of material type on selected physical properties of sintered pellets

a)

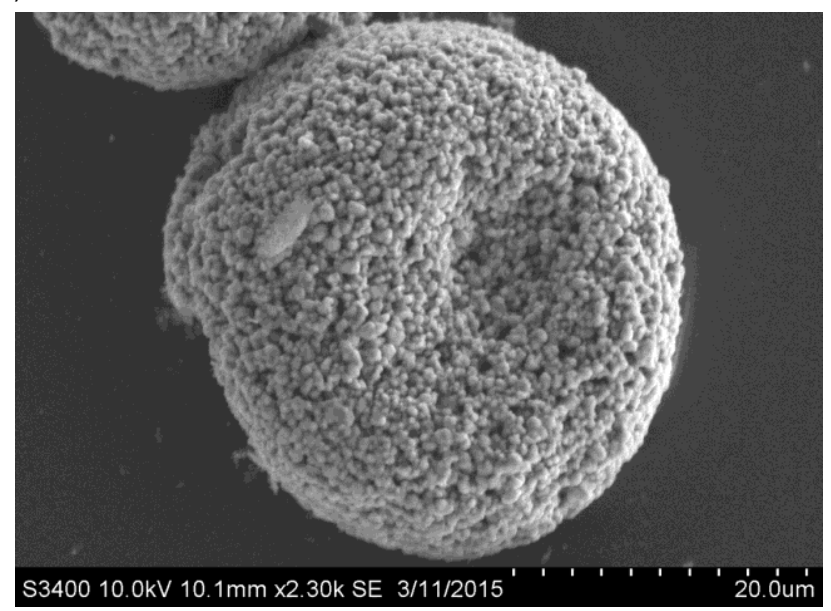

b)

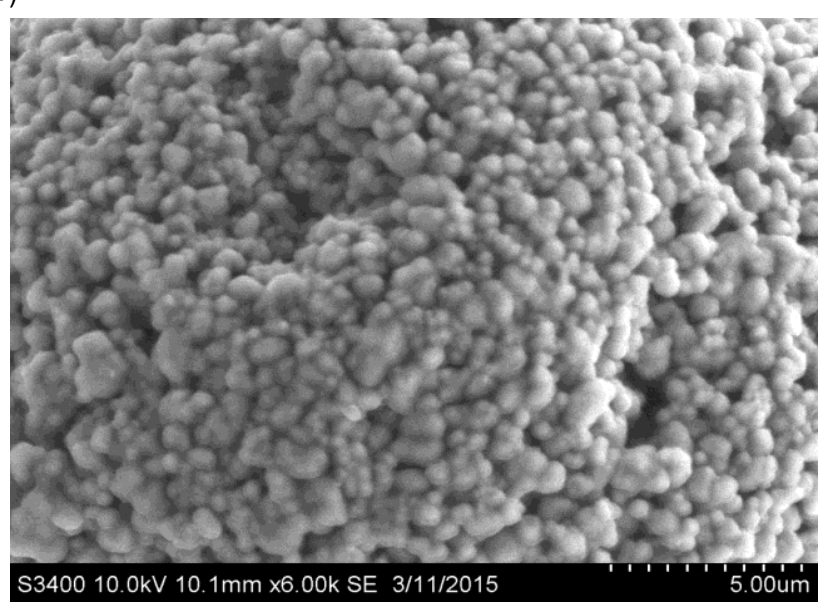

Fig. 6. SEM micrograph of $\mathrm{BaTiO}_{3}$ granulate in two different magnifications: $x 2.30 \mathrm{k}(\mathrm{a})$ and $\times 6.00 \mathrm{k}(\mathrm{b})$ 
The pressing and sintering of the samples caused the improving of phase composition of $\mathrm{BaTiO}_{3}(1)$ pellet. The XRD pattern of $\mathrm{BaTiO}_{3}(1)$ presented in Fig. 7 is better than in the case of granulate.

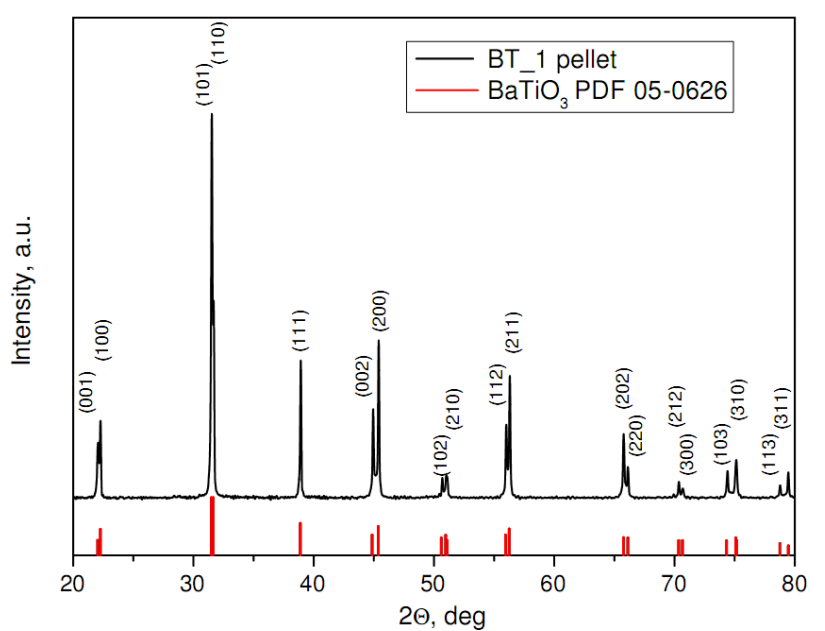

Fig. 7. XRD pattern of $\mathrm{BaTiO}_{3}(1)$ pellet

a)

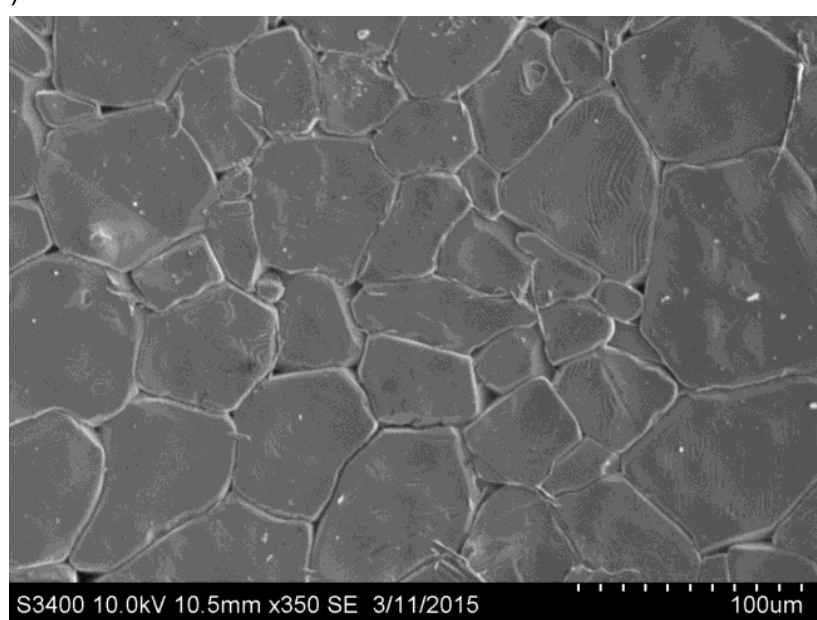

b)

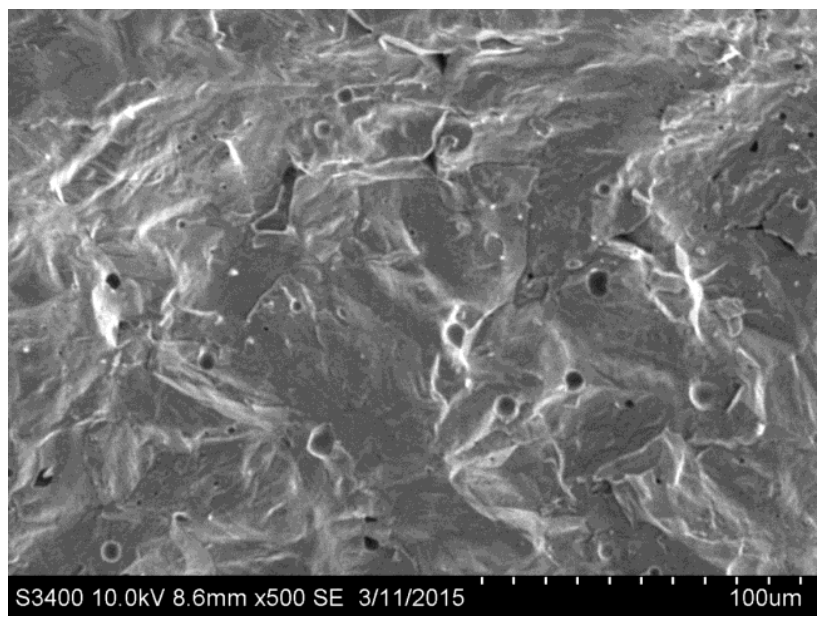

Fig. 8. SEM micrograph of $\mathrm{BaTiO}_{3}(1)$ pellet (a) and the fracture surface $(b)$
The SEM micrographs of $\mathrm{BaTiO}_{3}(1)$ pellet presented in Fig. 8a reveal the densification of the grains due to compacting process. The small pores indicated in the Fig. $8 \mathrm{~b}$ are a result of densification process and correspond to the density of $\mathrm{BaTiO}_{3}(1)$ pellet shown in Tab. 1. The smaller pores have a dimension of a few micrometers which is in agreement with the results of Yoon and Lee (2004). The size of the grains is very diversified. In the microstructure the large number of the grains with the size of $60-90 \mu \mathrm{m}$, and smaller number of grains with size between 1 and $3 \mu \mathrm{m}$ are observed (Fig. 8a).

To confirm the application of sintered $\mathrm{BaTiO}_{3}$ ceramic in multilayer actuators the additional mechanical properties i.e., the hardness, the flexural strength, the fracture toughness and the coefficient of thermal expansion were determined. The value of fracture toughness of $0.83 \mathrm{MPa} \cdot \mathrm{m}^{1 / 2}$ is comparable with the results of research of perovskite-type $\mathrm{BaTiO}_{3}$ ceramics conducted by Hwang and Niihara (1998). The hardness of the $\mathrm{BaTiO}_{3}(1)$ beam was equal to $3.09 \mathrm{GPa}$, the value of the bending strength was $78.1 \mathrm{MPa}$, while the coefficient of thermal expansion reached $4.75 \cdot 10^{-6} 1 / \mathrm{K}$.

\section{CONCLUSIONS}

The spherical grains of the size about $500 \mathrm{~nm}$ were indicated on SEM micrographs of powder but these small grains have an easy tendency to create agglomerates. The small value of the specific surface area of both powder and granulate ensured the good properties of material mouldability and finally allowed to receive sinters of high density. Obtainment of the high density of sinters was confirmed by the results of the apparent density and additionally photos of microstructure. The purity of powder, granulate and sinters was controlled by determining the phase compositions, which in all cases revealed the almost perfect barium titanate phase. The values of hardness, flexural strength, fracture toughness and coefficient of thermal expansion confirmed the usability of prepared perovskite-type $\mathrm{BaTiO}_{3}$ ceramic material on multilayer actuators. The microstructure of the pellets is comparable with the results found in the literature. However, to increase the dielectric constant of $\mathrm{BaTiO}_{3}$, it is expected to produce fine-grained microstructure of ceramic material. It is possible, by special thermal treatment of $\mathrm{BaTiO}_{3}$ pellets to get the smaller size of particles.

\section{REFERENCES}

1. Biglar M., Gromada M., Stachowicz F., Trzepieciński T. (2015), Optimal configuration of piezoelectric sensors and actuators for active vibration control of a plate using a genetic algorithm, Acta Mechanica, 226(10), 3451-3462.

2. Cai W., Fu C., Gao J., Guo Q., Deng X., Zhang C. (2011), Preparation and optical properties of barium titanate thin films, Physica $B$, 406, 3583-3587.

3. Choi M.-S., Kim S.-H., Kim Y.-H., Kim I.W., Jeong S.-J., Song J.S., Lee J.-S. (2008), Application of Ag-ceramic composite electrodes to low firing piezoelectric multilayer ceramic actuators, Journal of Electroceramics, 20, 225-229.

4. Duran P., Gutierrez D., Tartaj J., Moure C. (2002), Densification behaviour, microstructure development and dielectric properties of pure $\mathrm{BaTiO}_{3}$ prepared by thermal decomposition of $(\mathrm{Ba}, \mathrm{Ti})$-citrate polyester resins, Ceramics International, 28, 283-292. 
5. Ertuğ B. (2013), The overview of the electrical properties of barium titanate American Journal of Engineering Research, 2(8), 1-7.

6. Hackenberger W.S., Pan M.-J., Vedula V., Pertsch P., Cao W., Randall C.A., Shrout T.R. (1998), Effect of grain size on actuator properties of piezoelectric ceramics, Smart Structures and Materials 1998: Smart Materials Technologies, 3324, 28-34.

7. Hwang H.J, Niihara K. (1998), Perovskite-type $\mathrm{BaTiO}_{3}$ ceramics containing particulate SiC: Part II Microstructure and mechanical properties, Journal of Materials Science, 33, 549-558.

8. Kao C.F., Yang W.D. (1999), Preparation of barium strontium titanate powder from citrate precursor, Applied Organometallic Chemistry, 13, 383-397.

9. Kholodkova A., Danchevskaya M., Fionov A. (2012), Study of nanocrystalline barium titanate formation in water vapour conditions, NANOCON Conference, 23-25.10.2012, Brno, Czech Republic.

10. Kim H.-T., Kim J.-H., Jung W.-S., Yoon D.-H. (2009), Effect of starting materials on the properties of solid-state reacted barium titanate powder, Journal of Ceramic Processing Research, (10)6, 753-757.

11. Luo J, Qiu J., Zhu K., Du J. (2011), Effects of the calcining temperature on the piezoelectric and dielectric properties of 0.55PNN0.45PZT ceramics, Ferroelectric, 425(1), 90-97.

12. Miot C., Proust C., Husson E. (1995), Dense ceramics of $\mathrm{BaTiO}_{3}$ produced from powders prepared by a chemical process, Journal of European Ceramic Society, 15, 1163-1170.

13. Moura F., Simoes A.Z., Aguiar E.C., Nogueira I.C., Zaghete M.A., Varela J.A., Longo E. (2009), Dielectric investigations of vanadium modified barium zirconium titanate ceramics obtained from mixed oxide method, Journal of Alloys and Compounds, 479, 280-283.

14. Nguyen D.Q., Lebey T., Castelan P., Bley V., Boulos M., Guillemet-Fritsch S., Combettes C., Durand B. (2007), Electrical and physical characterization of bulk ceramics and thick layers of barium titanate manufactured using nanopowders, Journal of Materials Engineering and Performance, 16(5), 626-634.
15. Othman K.I., Hassan A.A., Abdelal O.A.A., Elshazly E.S., Ali M.E.-S., El-Raghy S.M., El-Houte S. (2014), Formation mechanism of barium titanate by solid-state reactions, International Journal of Scientific\& Engineering Research, (5)7, 1460-1465.

16. Prado L.R., de Resende N.S., Silva R.S., Egues S.M.S., SalazarBanda G.R. (2016), Influence of the synthesis method on the preparation of barium titanate nanoparticles, Chemical Engineering and Processing: Process Intensification, 103, 12-20.

17. Stojanovic B.D. (1999), Advanced in Sintered Electronic Materials, Advanced Science and Technology of Sintering, Kluwer Academic/Plenum Publishers, New York.

18. Vijatović M.M., Bobić J.D., Stojanović B.D. (2008), History and challenges of barium titanate: Part II, Science of Sintering, 40, 235-244.

19. Yoon D.-H., Lee B.I. (2004), Processing of barium titanate tapes with different binders for MLCC applications: Part I: Optimization using design of experiments, Journal of European Ceramic Society, 24 739-752.

20. Yoshikawa S., Shrout T. (1993), Multilayer piezoelectric actuators structures and reliability, AIAA/ASME/ASCE IAHS/ASC Structures, Structural Dynamics, and Materials Conference, 34th and AlAA/ASME Adaptive Structures Forum, La Jolla, CA, 19-22.04.1993, Technical Papers. Pt. 6, 3581-3586.

21. Zheng P., Zhang J.L., Tan Y.Q., Wang C.L. (2012), Grain-size effects on dielectric and piezoelectric properties of poled $\mathrm{BaTiO}_{3}$ ceramics, Acta Materialia, 60, 5022-5030.

The research leading to these results has received funding from the People Programme (Marie Curie Actions) of the European Union's Seventh Framework Programme FP7/2007-2013/ under REA grant agreement No. PITN-GA-2013-606878. 